\title{
Nutritional Status of Colorectal Cancer (CRC) Patients Undergoing Conventional Cancer Therapies
}

\author{
Mittu Mohan ${ }^{1}$, Jidhi Elsa John ${ }^{2}$ \\ ${ }^{I}$ (Lecturer, Dept. of Home Science, Vimala College, Calicut University, Thrissur, India) \\ 2 (PG student, Dept. of Home Science, Vimala College, Calicut University, Thrissur, India)
}

\begin{abstract}
Conventional cancer therapies are anti-cancer therapies taken by cancer patients with a purpose to achieve ultimate cure. Nutritional status of cancer patients undergoing such cancer therapies is very crucial as they determine their quality of life during as well as after therapy. However there are some common nutritional problems that occur as a result of the disease, treatment or both. So the main nutritional goal is to prevent or reverse nutrient deficiencies, to preserve lean-body mass, to minimize nutrition related side effects and to maximize the quality of life. So the aim of the present study is to gain a better understanding on the nutritional status, food consumption anddietary pattern of the subjects undergoing various conventional cancer therapies. Therefore a survey with the aid of a well formulated interview schedule assessed the nutritional status and health of 80 colorectal cancer patients of 35-65 years from various hospitals of Thrissur and Kozhikode districts. On the basis of the salient observations made in the study, in corporation with the quantitative and qualitative data, it can be concluded that the colorectal cancer patients undergoing various conventional cancer treatment faced many health and nutrition related problems.
\end{abstract}

Keywords: Colorectal Cancer (CRC), Conventional cancer therapy, Nutritional status, Dietary habits, health problems and side effects.

\section{Introduction}

Colorectal cancer, commonly known as bowel cancer, is a cancer from uncontrolled cell growth in colon, rectum or appendix [1]. Adenocarcinoma of the colon is the most common malignancy of the gastrointestinal tract and is major cause of morbidity and mortality worldwide.Currently, death due to colorectal cancer is the third leading cause of cancer-related mortality in Western World and Asian countries [2]. It is the third most common cancer in men and the second most common cancer in women [3]. The burden of CRC has risen rapidly in some economically developed Asian countries like Japan, South Korea and Singapore. Fortunately, the age adjusted incidence rates of CRC in all the Indian cancer registries are very close to the lowest rates in the world. However the specific cause of colon and rectal cancer (CRC) is still unknown. There are several interrelated risk factors under investigation. Environmental, nutritional, inherited factors and preexisting diseases are all associated with this cancer.

Conventional therapies are medical treatments used to treat people with cancer. Surgery, radiotherapy, chemotherapy, hormonal and biological therapies are some of the conventional cancer treatments [4].These treatments are dictated based on the size, location, extent of the tumor and the patient's general health.Sometimes two or more forms of treatments are also combined.The goal of treating cancer with conventional agents is to prevent cancer cells from multiplying, invading, and metastasizing. The ultimate aim of any cancer therapy is to achieve a cure. Usually conventional therapies present several problems during treatment.The major complications being alopecia,stomatitis, mouth sores, loss of appetite, constipation, erythema, hyper-pigmentation and many more.It's seen that the subjects lose a significant amount of weight during these treatments and have compromised eating abilities afterwards.Cancer and cancer treatments may affect taste, smell, appetite, and the ability to eat enough food or absorb the nutrients from food. This can cause malnutrition which significantly affects the nutritional status.So nutrition therapy is much needed for cancer patients to get the nutrients they need to keep up their body weight and strength, keep body tissues healthy, and fight infection.

According to American Cancer Society about one-thirds of the cancer deaths are preventable [5]. The role of nutrition inthis is vitally important in the treatment of cancer patients.Cancer prevention depends to a large degree on the overall quality of diet and ability to maintain a healthy weight.So the overall aim of the study was to gain a better understanding on the nutritional status and related problems and complications faced by CRC patients undergoing treatment.Therefore the accomplishment of such studies will help to understand more on health related issues faced by the subjects on or during the process of treatment. 


\section{Materials and Methods}

Eighty colorectal cancerpatients between the age group 35-65 years undergoing conventional therapies atAmala Cancer Centre of Thrissur district and Kozhikode Medical College were selected randomly. The study comprised a documentation of systematic investigations onsocioeconomic status of the families, anthropometric measurements, biochemical analysis, clinical and dietary assessment of the selected respondents by using a well formulated interview schedule. The subjects were interviewed personally using these schedules. Anthropometric parameters like Body Mass Index (BMI), Waist to hip ratio (WHR) and Mid upper arm circumference (MUAC) were measured to determine any unintentional weight loss or muscle wasting if any owing to treatment. Hemoglobin and WBC levels were assessed.Clinical examinations were done with the help of a physician.Dietary assessment which provides information on adequacy of food intake was taken by 24 hour recall and by using Food Frequency Questionnaire (FFQ).All the data pertaining to the nutritional status after collecting was processed and analyzed using statistical tools like Karl Pearson's Coefficient of Correlation and't'- test.

\section{Results and Discussion}

\subsection{Personal and Socio-economic characteristics}

Eighty colorectal cancerpatients, 50 males and 30 females undergoing conventional therapies were studied to understand their nutritional status during treatment. 46 per cent of colorectal cancer patients belonged to the age group of 55-65 years with a mean age of 57 years. This clearly states that incidence of colorectal cancer peaks after the age of 55years. Most persons are at an average risk of developing colorectal cancer at an age over 55years and more frequently seen in males compared to females [6]. Socio-economic status revealed that majority (53 per cent) of the subjects were employed and belonged to a high income group. Thirty nine per cent of the patients interviewed were Christians, 36 and 25 per cent being Hindus and Muslims.Nuclear family system was observed among 87 per cent.

Table 1: Personal and Socio-economic characteristics.

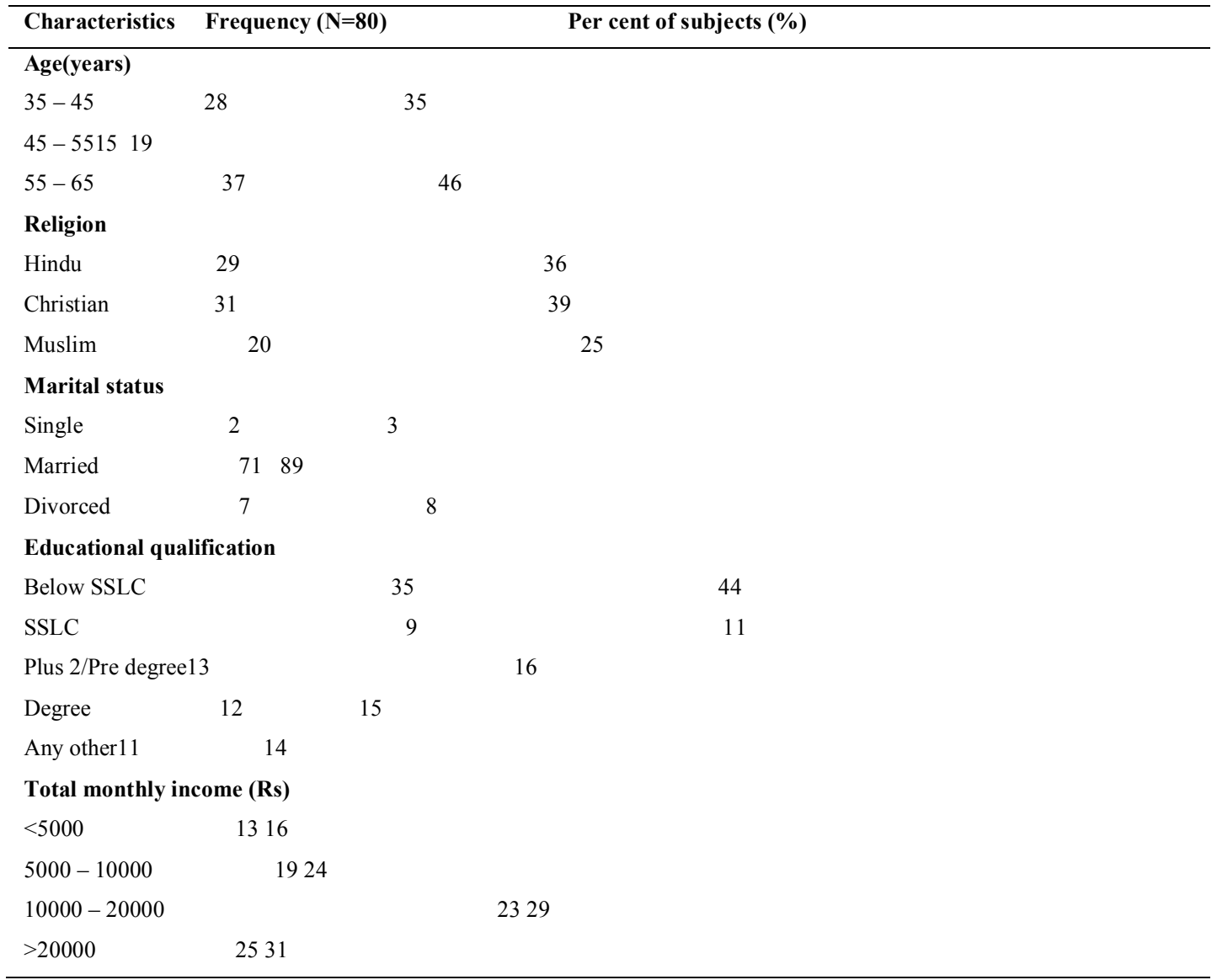




\subsection{Nutritional status of Cancer patients undergoing therapy}

\subsubsection{Anthropometry and Biochemical status of the respondents}

Monitoring of anthropometric and biochemical measurements can provide valuable information on changes in nutritional status.

\subsubsection{Mean weight distribution of the subjects}

The mean weight of CRC patients was found out. Weight loss is common among patients with cancer and is usually present from the time of diagnosis.

Table 2: Mean weight distribution of the subjects during therapy

\begin{tabular}{|c|c|c|c|c|}
\hline \multirow{2}{*}{ Sample } & Initial weight & Current weight & \multirow{2}{*}{ 't'-value } & \multirow{2}{*}{ p-value } \\
\cline { 2 - 3 } & Mean & Mean & & \\
\hline Male & $60.07 \pm 4.63$ & $53.13 \pm 4.69$ & $12.937^{* *}$ & $<0.001$ \\
\hline Female & $62.10 \pm 5.34$ & $55.70 \pm 5.81$ & $17.764^{* *}$ & $<0.001$ \\
\hline
\end{tabular}

** Correlation is significant at the 0.01 level

The patients self-reported earlier weight at the time of treatment was the reference of unintentional weight loss, all of which the patients had lost considerable weight, mean $6.5 \pm 2.5 \mathrm{Kg}$. The mean initial weight of males were 60 and for females it was 62.Details of current weight showed that there tend to be a decrease in the mean weight when compared with the initial ( 53 for males and 55 for females). ' $t$ ' test employed showed a significant change between initial and current weight at 0.01 level $(p<0.01)$. Uncontrolled weight loss can negatively affect quality of life, delay or prevent treatment completion, prolonging healing, and increased risk of complications. Current weight that is 20 per cent below ideal body weight is also an indication of nutritional risk.

\subsubsection{Body mass index (BMI) of CRC patients}

Table 3: Body Mass Index (BMI) of the respondents

\begin{tabular}{|l|c|c|}
\hline \multicolumn{1}{|c|}{$\mathrm{BMI}\left(\mathrm{Kg} / \mathrm{m}^{2}\right)$} & Initial BMI & Final BMI \\
\hline Underweight & - & 98 \\
\hline Normal & 74 & 1 \\
\hline Overweight & 26 & - \\
\hline Obesity & - & 100 \\
\hline Total & 100 & \\
\hline
\end{tabular}

*WHO, 2004

BMI of 50 males and 30 females was assessed. It was found that prior to the treatments the subjects who were rated over weight was 26 per cent and the subjects who were assessed normal were 74 per cent. When the BMI of the subjects was assessed during the course of treatment it was found that 98 per cent of them had a normal BMI and 1 per cent each were assessed of being underweight and overweight respectively. Measuring obesity by Body Mass Index (BMI) fails to account for fat distribution and quantity for colorectal cancer patients [7].

Unintentional weight loss has often been reported in cancer patients and is regarded as a stronger variable for detection of malnutrition. Therefore percentage weight loss of cancer patients during therapy was studied and is presented in Fig1.Unintentional weight loss has often been reported in cancer patients and is regarded as a stronger variable for detection of malnutrition. The figure shows that 38 per cent had a weight loss in between 5 to 10 per cent and 40 per cent had a weight loss between 10 to15 per cent. 9 per cent of the subjects had a weight loss between 15 to 20 per cent while the rest were negligible.It is generally accepted that an unintentional loss in body weight greater than 10 per cent during cancer treatments is a serious threat to morbidity and mortality. 


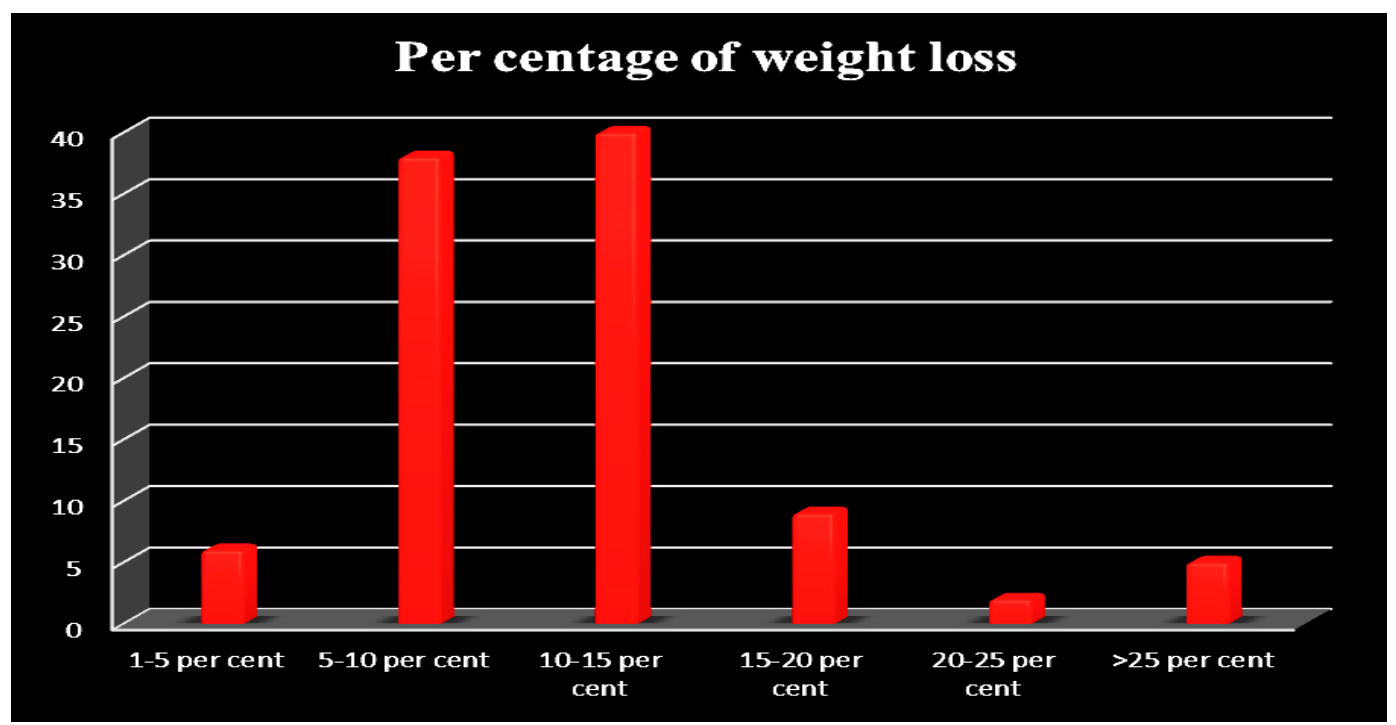

Figure 1: Percentage weight loss of CRC patients during therapy

Table 4: Other anthropometric and biochemical indices of the respondents

\begin{tabular}{|c|c|c|c|}
\hline *Categories & Range & Frequency $(\mathrm{N}=80)$ & Per cent of subjects (\%) \\
\hline Waist -hip ratio(WHR) & $\begin{array}{l}\text { Low } \\
\text { At risk }\end{array}$ & $\begin{array}{l}- \\
80\end{array}$ & $\begin{array}{c}- \\
100\end{array}$ \\
\hline \multicolumn{4}{|c|}{ Mid upper arm circumference (MUAC), $(\mathrm{cm})$} \\
\hline Males & $\begin{array}{l}\text { Normal }(\geq 23) \\
\text { Malnourished }(<23)\end{array}$ & $\begin{array}{c}50 \\
-\end{array}$ & $\begin{array}{l}62 \\
-\end{array}$ \\
\hline Females & $\begin{array}{l}\text { Normal }(\geq 22) \\
\text { Malnourished }(<22)\end{array}$ & $\begin{array}{c}30 \\
-\end{array}$ & $\begin{array}{c}38 \\
-\end{array}$ \\
\hline Hemoglobin levels(g/dl) & $\begin{array}{l}\operatorname{Low}(<13.5) \\
\text { Normal (13.5-17) }\end{array}$ & $\begin{array}{c}80 \\
-\end{array}$ & $\begin{array}{c}100 \\
-\end{array}$ \\
\hline WBC levels(mcg/l) & $\begin{array}{l}\text { Below } 4500 \\
\text { Normal }(4500-11000)\end{array}$ & $\begin{array}{l}53 \\
27\end{array}$ & $\begin{array}{l}66.25 \\
33.75\end{array}$ \\
\hline
\end{tabular}

*National Institute of Nutrition, 2003.

Waist to hip ratio of the colorectal cancer (CRC) patients were measured.All the subjects had a waist to hip ratio $\geq 0.7$ which indicated that they were at risk. The measurement of Mid Upper Arm Circumference (MUAC) serves as an index for skeletal muscle mass and protein reserve. Majority (62 per cent males and 38 per cent females) had a normal MUAC. Mid Upper Arm Circumference has been promoted as an alternative method for measuring wasting for all age groups.

Biochemical estimation is done for the purpose to give reasonable estimates of prognosis, response to any therapy used or likely course of disease [8]. Biochemical analysis such as haemoglobin and White blood cell count (WBC) levels of the subjects was recorded. The data showed that all the respondents had a low $\mathrm{Hb}$ level which shows that they were anaemic and WBC levels clearly indicated that 53 per cent of the subjects had low WBC counts.Karl Pearson's Coefficient of correlation was employed to compare the relationship between iron intakes and haemoglobin levels of cancer patients. Statistical analysis revealed that there was no significant correlation between iron intakes and haemoglobin levels (.044). Although the iron intake by the respondents met 70 to 80 per cent of the adult requirement, the antitumor therapies have found to interfere with the effective absorption and utilization of iron in the body. So the statistical analysis revealed a no significant relation between iron intake and $\mathrm{Hb}$ levels.

Clinical features like hair, eyes, teeth, skin and gums were observed which showed extreme side effects like hair loss, pale eyes, rough skin as side effects of therapy.

\subsubsection{Food Consumption pattern of subjects}

Food consumption pattern of the subjects were studied with respect to food habits, dietary pattern and frequency of use of food items. Most of the subjects werehabitual non- vegetarians and majority of them had 
three major meals a day.Most of the respondents (64 per cent) didn't skip any meal, while 33 per cent skipped breakfast. The main reason for skipping meal was due to lack of time and dislike for food. Significant weight loss is common in patients undergoing neo-adjuvant chemo radiotherapy as there is a strong dislike to food or loss of appetite, and they are likely to have significant nutritional problems. Habit of consuming food from outside was studied showed 62 per cent of the subjects consumed food from outside.

Food frequency questionnaire (FFQ) was used to assess the food consumption pattern among the colorectal cancer patients. Through this method it was understood that the food intake of the patients was very low compared to that of RDA. Food items such as cereals, pulses, milk and milk products, fish, fats and oils, sugars and jaggery were consumed on a daily basis by the patients. Foods such as green leafy vegetables, other vegetables, roots and tubers, meat were consumed moderately. Less frequently used food group was poultry and least frequently used food was fruits. Through this study it was understood that even though major food groups were included in their diet, the intake of food was very low as they were undergoing cancer treatments. And for this reason, their food intake did not reach the required dietary allowance needed for a normal adult man/woman.

\subsubsection{Food intake of CRC patients}

The food intake of the subjects was determined by 24 hour recall method to assess the quantity and quality of nutrients present in the diet. From the amount of food consumed nutrient intake was calculated and compared with RDA.

Table 5: Food intake of the subjects

\begin{tabular}{|l|c|c|c|c|c|c|}
\hline \multirow{2}{*}{\multicolumn{1}{|c|}{ Food groups }} & \multicolumn{2}{|c|}{ *RDA } & \multicolumn{2}{c|}{ Mean food intake(g) } & \multicolumn{2}{c|}{ Per cent of RDA met } \\
\cline { 2 - 7 } & $\begin{array}{c}\text { Males } \\
(\mathrm{n}=50)\end{array}$ & $\begin{array}{c}\text { Females } \\
(\mathrm{n}=30)\end{array}$ & Males & Females & Males & Females \\
\hline Cereals & 375 & 270 & 220 & 110 & 58.6 & 40.7 \\
\hline Pulses & 75 & 60 & 43 & 47 & 57.3 & 78.3 \\
\hline Green leafy vegetables & 100 & 100 & 45 & 51 & 45 & 51 \\
\hline Other vegetables & 200 & 200 & 143 & 157 & 71.5 & 78.5 \\
\hline Roots and tubers & 200 & 200 & 123 & 117 & 61.5 & 58.5 \\
\hline Fruits & 100 & 100 & 15 & 26 & 15 & 26 \\
\hline Milk & 300 & 300 & 257 & 220 & 85.6 & 73.3 \\
\hline Meat and fish & 75 & 60 & 46 & 54 & 61.3 & 90 \\
\hline Fats and oils & 25 & 20 & 21 & 15 & 84 & 75 \\
\hline Sugar and jaggery & 20 & 20 & 19 & 15 & 95 & 75 \\
\hline
\end{tabular}

*National Institute of Nutrition, 2011.

The above TABLE clearly indicates the food intake of the subjects (50 males and 30 females). Although the food requirements of cancer patients are high, the intakes of various food groups by the subjects were found too low when compared with RDA.From the TABLE it can be concluded that the cereal consumption was less compared to the RDA, where the percentage met only 58.6 per cent in males and 40.7 per cent in females. The consumption of pulses met 57.3 per cent in males and 78.3 per cent in females. The green leafy vegetables only met 45 and 51 per cent respectively for both males and females. This clearly indicated that the consumption of green leafy vegetables by the respondents did not meet their daily requirements. The consumption of fruits was considered to have a least percentage ( 15 per cent and 26 per cent) compared to the rest of the food groups. Fiber in the form of fruits and vegetables has been considered beneficial lowering one's risk of colorectal cancer. Most of the respondents consumed milk in the form of tea and coffee which constituted about 85.6 per cent in males and 73.3 per cent in females. Regarding meat and fish consumption, fish was most frequently consumed by the respondents compared to that of meat. The percentage of RDA met for males regarding fish consumption was 61.3 per cent for males and 90 per cent for females. The percentage of RDA met by fat, oil, sugar and jaggery was high. Increasing fruit and vegetable consumption and decreasing the intake of fats and sugar has shown to improve the complications associated with CRC. 


\subsubsection{Nutrient intake of CRC patients undergoing therapy}

The mean nutrient intake of the subjects (Males and Females) were calculated and compared with the RDA. Details of the nutrient intake of the subjects are given in TABLE 6.

Table 6: Nutrient intake of male and female CRC patientsundergoing therapy

\begin{tabular}{|l|c|c|c|c|c|c|c|c|}
\hline \multicolumn{3}{|c|}{ MALES } & \multicolumn{5}{c|}{ FEMALES } \\
\hline Nutrients & *RDA & $\begin{array}{l}\text { Mean nutrient } \\
\text { intake }\end{array}$ & t-value & $\begin{array}{l}\text { Per cent of } \\
\text { RDA met }\end{array}$ & $*$ RDA & $\begin{array}{l}\text { Mean nutrient } \\
\text { intake }\end{array}$ & t-value & $\begin{array}{l}\text { Per cent of } \\
\text { RDA met }\end{array}$ \\
\hline Energy (Kcal) & 2320 & $1216.18 \pm 550$ & $14.19^{* *}$ & 52 & 1900 & $1080 \pm 521$ & $8.6^{* *}$ & 57 \\
\hline Protein (g) & 60 & $42 \pm 14.3$ & $8.8^{* *}$ & 70 & 55 & $37.6 \pm 12.5$ & $7.5^{* *}$ & 68 \\
\hline Fat (g) & 25 & $17.28 \pm 13.12$ & $4.15^{* *}$ & 69 & 20 & $14.5 \pm 7.5$ & $3.9^{* *}$ & 73 \\
\hline Calcium (mg) & 600 & $244.6 \pm 107.6$ & $23.3^{* *}$ & 41 & 600 & $236.6 \pm 133.3$ & $14.9^{* *}$ & 39 \\
\hline Iron (mg) & 17 & $14.8 \pm 7.01$ & $2.17^{* *}$ & 87 & 21 & $15.4 \pm 6.5$ & $4.5^{* *}$ & 73 \\
\hline $\begin{array}{l}\text { Ascorbic } \\
\text { acid(mg) }\end{array}$ & 40 & $18.6 \pm 9.41$ & $16^{* *}$ & 47 & 40 & $19.7 \pm 9.3$ & $11.8^{* *}$ & 49 \\
\hline Fiber (g) & 30 & $12.3 \pm 6.69$ & $18.64^{* *}$ & 41 & 30 & $11 \pm 5.22$ & $19.8^{* *}$ & 37 \\
\hline
\end{tabular}

*National Institute of Nutrition, 2011.

** Correlation is significant at the 0.01 level.

In the present study, data pertaining to the nutrient intake by the colorectal cancer (CRC) patients, both males and females, clearly indicated that the mean nutrient intake was inadequate when compared with the RDA. ' $t$ ' test was used to compare the nutrient intake of the cancer patients with reference standards. Statistical analysis revealed a significant relationship at 0.01 levels between the RDA and mean nutrient intake. The mean nutrient intake in both male and female respondents showed a sharp difference from the requirements. Antitumor therapy such as chemotherapy, radiation therapy, surgery or immunotherapy can contribute to nutritional alterations in patients by interfering with their ability to ingest digest and absorb adequately.

\section{IV.Conclusion}

The present study "Nutritional status of Colorectal Cancer (CRC) patients undergoing conventional cancer therapies" was carried out to assess the nutritional status of colorectal cancer patients undergoing various conventional treatments. On the basis of the salient observations made in the study, in corporation with the quantitative and qualitative data, it can be concluded that the colorectal cancer patients undergoing various conventional cancer treatment regimens faced many health and nutrition related problems during the treatments. Weight loss was one of the major side effects seen in patients undergoing treatments. As the side effects due to the treatment are so common, the nutritional status and quality of life (QOL) of such patients tend to show a steep decline. Therefore the dietary interventions planned for them should be adequate enough to prevent nutritional complications during each step of the treatment. The food habits should always be under check. The need for nutrition education for the subjects suffering from the same can help to promote nutritional awareness and good eating habits.

\section{References}

[1] Colorectal cancer, Wikipedia - The free Encyclopedia

[2] Colon and rectal cancer. (2007). National Cancer Institute.

[3] Colorectal Cancer Incidence and Mortality Worldwide in 2008- Summary, GLOBOCAN Cancer fact sheet: International Agency for Research on Cancer

[4] Conventional, complementary and alternative therapy. (2012). Macmillan Cancer support.

[5] American cancer society. (2001). "Cancer of the lower gastro international tract".P.86.

[6] Elliot, J. (2011). "Medifocus Guide on Colorectal cancer". (800) 965 -3002.P. 16.

[7] Acton, A. (2011). "Nutrition disorders: advances in research and treatment". Published by scholarly editors, Atlanta.P. 37.

[8] Chawla, R. (2003). Practical clinical biochemistry: Methods and interpretations (New Delhi, Jaypee brother medical publishers). 